\title{
Article \\ Vegetative and Reproductive Response to Fruit Load in Two Jojoba (Simmondsia chinensis) Cultivars
}

\author{
Aviad Perry ${ }^{1,2}$, Noemi Tel-Zur ${ }^{3}\left[\right.$ and Arnon Dag ${ }^{2, *(1)}$ \\ 1 The Albert Katz International School for Desert Studies, The Jacob Blaustein Institutes for Desert Research, \\ Sede Boqer Campus, Ben-Gurion University of the Negev, Sede Boqer 84990, Israel; aviadper@post.bgu.ac.il \\ 2 Institute of Plant Sciences, Agricultural Research Organization, Gilat Research Center, Gilat 85280, Israel \\ 3 French Associates Institute for Agriculture and Biotechnology of Drylands, The Jacob Blaustein Institutes for \\ Desert Research, Sede Boqer Campus, Ben-Gurion University of the Negev, Sede Boqer 84990, Israel; \\ telzur@bgu.ac.il \\ * Correspondence: arnondag@agri.gov.il
}

Citation: Perry, A.; Tel-Zur, N.; Dag, A. Vegetative and Reproductive Response to Fruit Load in Two Jojoba (Simmondsia chinensis) Cultivars. Agronomy 2021, 11, 889. https:// doi.org/10.3390/agronomy11050889

Academic Editor: Yehoshua Saranga

Received: 21 March 2021

Accepted: 28 April 2021

Published: 1 May 2021

Publisher's Note: MDPI stays neutral with regard to jurisdictional claims in published maps and institutional affiliations.

Copyright: ( $\odot 2021$ by the authors Licensee MDPI, Basel, Switzerland. This article is an open access article distributed under the terms and conditions of the Creative Commons Attribution (CC BY) license (https:// creativecommons.org/licenses/by/ $4.0 /)$.

\begin{abstract}
Jojoba (Simmondsia chinensis) is a wax crop cultivated mainly in arid and semi-arid regions. This crop has been described as an alternate-bearing plant, meaning that it has a high-yield year ("on-year") followed by a low-yield year ("off-year"). We investigated the effect of fruit load on jojoba's vegetative and reproductive development. For two consecutive years, we experimented with two high-yielding cultivars-Benzioni and Hazerim — which had opposite fruit loads, i.e., one was under an on-year load, while the other was under an off-year load simultaneously. We found that removing the developing fruit from the shoot during an off-year promotes further vegetative growth in the same year, whereas in an on-year, this action has no effect. Moreover, after fruit removal in an on-year, there was a delay in vegetative growth renewal in the consecutive year, suggesting that the beginning of the growing period is dependent on the previous year's yield load. We found that seed development in the 2018 season started a month earlier than in the 2017 season in both cultivars, regardless of fruit load. This early development was associated with higher wax content in the seeds. Hence, the wax accumulation rate, as a percentage of dry weight, was affected by year and not by fruit load. However, on-year seeds stopped growing earlier than off-year seeds, resulting in smaller seeds and an overall lower amount of wax per seed.
\end{abstract}

Keywords: jojoba; alternate bearing; vegetative growth; seed development; sink-source relationship

\section{Introduction}

Jojoba (Simmondsia chinensis (Link) Schneider) is a wax crop; it is a wind-pollinated, dioecious perennial evergreen shrub, native to the Sonoran Desert [1,2]. It is mainly cultivated in arid and semi-arid regions in Argentina, Mexico, the United States, Peru, India, South Africa, and Israel [3,4]. Jojoba has been grown in Israel since the late 1980s [5]. In the first two decades, it was considered as a niche market crop, with a small cultivation area, but nowadays, due to increased world demand, the cultivated area has grown from about 730 hectares in 2012 to 2400 hectares in 2021, making Israel a leading jojoba producer [6]. The primary market for the odorless wax is the cosmetics industry, but it is a suitable, high-quality raw material for other sectors, such as biodiesel, pharmaceuticals, plastics, engine lubricants, and printing ink [4-8]. Jojoba seeds are one of the world's only known sustainable sources of liquid wax esters, and they are used as a substitute for the familiar oils that were once obtained from the sperm whale, which was hunted nearly to extinction [9]. The wax esters from jojoba seeds are monounsaturated long-chain fatty acids (C20-C24) and fatty alcohols (C20-C24), which can accumulate to up to $60 \%$ of the seed's weight $[10,11]$.

Jojoba plants grow during the spring and autumn. During these growth periods, the branches elongate, and new nodes, leaves, and flower buds develop; in most female jojoba 
genotypes, flower buds differentiate at every second node on the leaf axil $[12,13]$. This makes the vegetative development of the current year, i.e., new nodes, an essential trait for productivity as it represents the following year's yield potential [14]. In Israel, blooming occurs in the second half of the winter, from early January till mid-March, depending on the cultivar and weather conditions $[5,15]$, because jojoba flower buds have a mandatory chilling period demand for flower bud dormancy break [14-17]. Fruit development takes six to seven months from pollination to ripening, depending on fruit load [1]. When ripe, the capsule dries, and with a gentle shake, the fruits fall to the ground where they are collected by suitable harvesters.

Jojoba has an alternate-bearing yield pattern, meaning that a high-yield year ("onyear") is followed by a low-yield year ("off-year") [18-21]. There are reports of alternate bearing in many perennial crops [22-24], including apples, olives, avocados, mangos, pistachios, and more; however, the processes leading to this pattern differ among species. The regulatory mechanisms of alternate bearing can be divided into environmental triggers, such as winter chilling, and endogenous factors, such as competition for sinks, repression of metabolic pathways, and hormonal regulation [22,23].

The alternate-bearing pattern is prevalent in jojoba's native environment, where 2.7 times and even five times higher yields have been found in years following low yield [21,25]. Purcell et al. [13], who conducted eight years of research with 100 jojoba cultivars, found that in off-years, the yield is only $10 \%$ to $50 \%$ of that in on-years. Nelson and Watson [19] suggested that jojoba retains this characteristic after observing an alternate-bearing yield pattern in their nitrogen fertilization experiment. Abd El Mohsen and Abd Allatif [26] also reported an alternate fruit-bearing pattern in 26 different jojoba cultivars in Egypt.

Fruit load in jojoba affects seed size and weight, which are smaller in high-yield seasons [18] and can therefore cause problems for mechanical harvesting. The harvester collects the seeds from the ground and separates them from the soil particles; this is more challenging with small seeds and can result in yield losses. In addition, high fruit load delays ripening, pushing it closer to the rainy season, which can damage the seeds lying on the ground or induce germination [27].

Understanding the plant's behavior under variable fruit load will shed light on the mechanisms controlling alternate bearing in jojoba; in addition, it can help improve agromanagement and provide economic benefits for the farmers. Despite its importance, there are only a few studies on this subject in jojoba, and the factors controlling alternate bearing in this plant are unknown. We hypothesized that competition between sinks is the main factor affecting the rate of vegetative development, thus controlling the following year's productivity. The objective of this work was to investigate the yearly cycle of commercial female jojoba cultivars by studying their vegetative and reproductive development, relative to fruit load, under field conditions.

\section{Materials and Methods}

\subsection{Plant Material}

Female plants of two local commercial cultivars, Benzioni and Hazerim, were monitored in two adjacent plots over two consecutive seasons, 2017 and 2018. Each year, a different set of plants was measured. The orchard was located in an arid zone (mean annual precipitation of $195 \mathrm{~mm}$ ), next to Kibbutz Hazerim $\left(31^{\circ} 14^{\prime} 45.9^{\prime \prime} \mathrm{N} 34^{\circ} 43^{\prime} 18.2^{\prime \prime} \mathrm{E}\right)$ in the northern Negev Desert region of Israel. Cv. Benzioni was planted in 2009 and cv. Hazerim in 2007, at a density of 1100 plants/ha, $5 \%$ male plants, planted in separate rows. The plants were irrigated and fertilized according to common practice: $750 \mathrm{~mm}$ /year with reclaimed wastewater. Fertilizer was applied from March till November via the irrigation system (fertigation) to final doses of 250, 100-150, and $250 \mathrm{~kg} /$ ha per year of nitrogen, phosphorus, and potassium (NPK), respectively [21]. 


\subsection{Yield}

The plots had opposite yield loads, as 2017 was an on-year for Hazerim and an off-year for Benzioni, and vice versa in 2018. Hazerim yielded 7070 and $2770 \mathrm{~kg}^{-1}$ seeds ha ${ }^{-1}$ in 2017 and 2018, respectively. Benzioni yielded 3060 and $4180 \mathrm{~kg}$ seeds ha ${ }^{-1}$ in 2017 and 2018 , respectively. The yield data were collected by the grower's commercial harvesting array [27].

\subsection{Vegetative Growth Measurements}

We measured six plants of each cultivar, which were separated from each other by one non-sampled plant. After pruning (in December), on each plant, six branches per side (east and west) with young, developed leaves were marked with tape behind the second node. We counted the nodes and measured the length of each main branch. In February, at anthesis, flower buds from three branches on each side were removed (fruit removal treatment). We calculated the seasonal branch elongation by subtracting the last (9 October 2017, and 20 August 2018) from the first measured length for each season, and the average node length by dividing the branch length by the number of nodes.

\subsection{Fruit Development}

Developing fruit and mature seeds were collected from plants in the row adjacent to that in which vegetative development was measured. Five fruits from each of the six plants were randomly picked during their development, starting from fruit set until seed maturation (12 and 10 times in 2017 and 2018, respectively). After seed maturation, seeds were randomly collected from the ground. Twelve fruits per cultivar were randomly sampled for fruit and seed mass on each sampling date. We weighed the seeds before and after drying in a $70^{\circ} \mathrm{C}$ oven for three days to determine dry seed mass (DW) and to calculate the water content. The following equation was used to calculate seeds per plant:

$$
\frac{\text { Seed yield }\left(\frac{\mathrm{kg}}{\mathrm{ha}}\right)}{\text { Dry seed mass }(\mathrm{g})}
$$

\subsection{Wax Content Analysis}

Twenty dried seeds (as described in the previous section) per cultivar were ground to a powder in a coffee grinder. The sample was then placed in a paper tube capped with cotton wool, weighed, and transferred to a Soxhlet extractor apparatus heated to $70{ }^{\circ} \mathrm{C}$ and filled with n-hexane for $6 \mathrm{~h}$. The paper tubes were then transferred to a $40^{\circ} \mathrm{C}$ oven to dry overnight, then weighed again, and the mass difference represented the mass of wax removed from the sample.

\subsection{Statistical Analysis}

All statistical analyses were performed in R 3.6.1 (R Core Team, 2019). To understand the effect of fruit removal on node development and branch elongation, and to test the effect of fruit load on seed development traits, two-tailed Student's $t$-tests were performed. To test the effect of the interaction between season and fruit removal treatment for each cultivar, two-way ANOVA tests were performed. In all of the tests, we used an alpha level of 0.05 .

\section{Results}

Vegetative growth of Hazerim in the 2017 season (on-year) was similar for both the control and fruit removal treatments, with an average of ca. 4.5 new nodes developing during the season (December-September) (Figure 1a). In the following season (2018, off-year), fruit removal led to an increase in node development, i.e., 7.9 new nodes in comparison to 5.6 in the control treatment $(P=0.083)$. The difference between treatments started in March, one month after removing the developing fruit. In contrast to the prior 
season, in 2018, vegetative growth did not cease in April; it continued throughout the seed development period in both treatments, but at a higher rate in the fruit removal treatment.

a

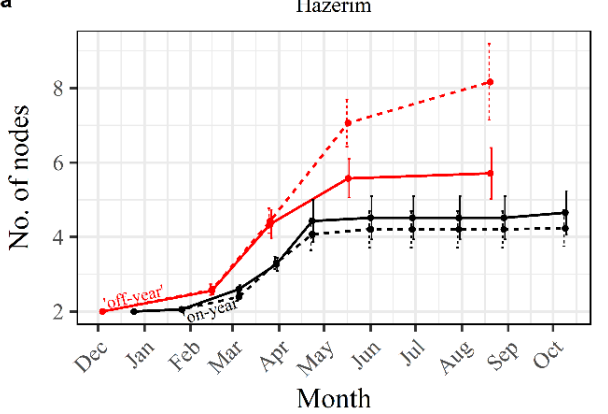

b

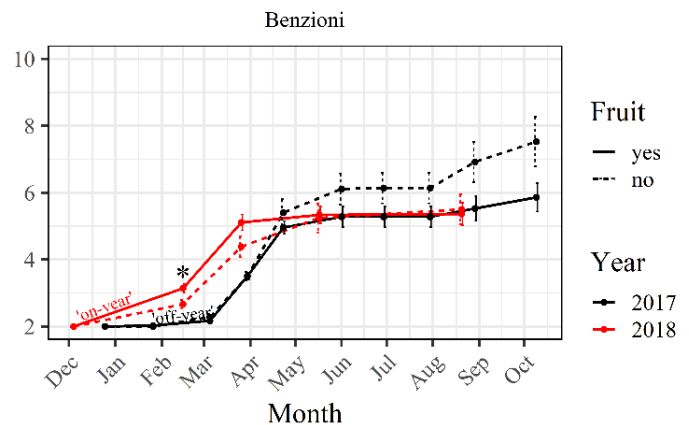

Figure 1. Effect of fruit removal on node number in cvs. Hazerim (a) and Benzioni (b). Values are mean \pm SE of six plants per cultivar. Data are presented for 2017 (black lines) and 2018 (red lines). We measured 12 branches on each plant, six of which had their fruit removed in February (dashed lines), and six that were untreated (solid lines). ${ }^{*}$ Significant difference $(P \leq 0.05, t$-test) between treatments in the same year for the same cultivar.

Benzioni, which had an alternate-bearing pattern opposite to that of Hazerim, showed an increase in the number of new nodes in the 2017 season (off-year) with an average of ca. 7.5 new nodes on the fruit removal branches compared to ca. 5.8 new nodes in the control treatment $(P=0.16)$ (Figure 1b). In 2018 (on-year), the development of the new nodes was similar, with an average of $~ 5.3$ in both treatments. In Benzioni, unlike Hazerim, node development stopped during the summer (May-July), regardless of treatment or fruit load (Figure 1). In both cultivars, vegetative growth started earlier in 2018 than in 2017, probably due to the warmer winter in 2018.

The number of nodes was lower for the control groups in the on-year than in the off-year in both cultivars. (Table 1). In Hazerim, a two-way ANOVA test revealed that there was no significant interaction between year and treatment. The effect of year was significant $(P \leq 0.05)$, and the effect of treatment was not. Seasonal branch elongation showed a trend similar to that of node development. In both cultivars, removing the fruit in an off-year resulted in longer branches. In 2017, the average gain in length for Hazerim was $4.3 \mathrm{~cm}$ for both treatment and control groups; in 2018, elongation was higher for the fruit removal treatment than for the controls; however, the differences were not significant $(P=0.25$, $t$-test; Table 1$)$. Branch elongation in Benzioni was higher for the fruit removal treatment than for the controls in $2017(P=0.093, t$-test $)$ and about the same for both treatments in 2018 (Table 1). In Hazerim, the effect of the year on branch elongation was significant $(P \leq 0.05$, two-way ANOVA), but in Benzioni, the fruit removal treatment had a stronger effect, although not significant $(P=0.064$, ANOVA).

Node length in Hazerim was affected by yield load, but not by treatment, as both groups showed similar results within the same season (Table 1). In 2017, the average node length was ca. $1.5 \mathrm{~cm}$, but in 2018 (off-year), it increased, albeit non-significantly, by 12\% (Table 1). In Benzioni, however, the treatment had an effect during the low-yield year, as removing the fruit increased the length of the node by $12 \%$ compared to the control $(P=0.08, t$-test; Table 1$)$. Under the high-yield load, this effect was not evident, with a similar average length for both treatments (Table 1). The Benzioni control treatment showed a significant difference $(P \leq 0.05, t$-test) in node length between seasons, with longer nodes in the on-year (Table 1). 
Table 1. Effect of yield load and fruit removal on number of nodes, branch elongation, and node length in Hazerim and Benzioni. Values are means of six plants per cultivar \pm SE. We measured 12 branches on each plant, six that bore fruit (control), and six with fruit removed (fruit removal). Presented data are for the last day of measurement in each year: Oct. 9, 2017 and Aug. 20, 2018.

\begin{tabular}{|c|c|c|c|c|c|c|c|c|}
\hline \multirow[t]{2}{*}{ Cultivar } & \multirow[t]{2}{*}{ Season } & \multirow[t]{2}{*}{ Yield Load } & \multicolumn{2}{|l|}{ No. of Nodes } & \multicolumn{2}{|c|}{$\begin{array}{l}\text { Seasonal Branch } \\
\text { Elongation }(\mathrm{cm})\end{array}$} & \multicolumn{2}{|c|}{ Node Length (cm) } \\
\hline & & & Control & $\begin{array}{l}\text { Fruit } \\
\text { Removal }\end{array}$ & Control & $\begin{array}{l}\text { Fruit } \\
\text { Removal }\end{array}$ & Control & $\begin{array}{l}\text { Fruit } \\
\text { Removal }\end{array}$ \\
\hline Hazerim & 2017 & High & $4.69 \pm 0.47^{\mathrm{B}}$ & $4.31 \pm 0.62$ & $4.83 \pm 0.77^{\mathrm{B}}$ & $4.37 \pm 0.92$ & $1.48 \pm 0.08$ & $1.52 \pm 0.08$ \\
\hline Hazerim & 2018 & Low & $5.66 \pm 0.91^{\mathrm{A}}$ & $7.90 \pm 1.20$ & $8.03 \pm 1.81^{\mathrm{A}}$ & $11.90 \pm 2.57$ & $1.66 \pm 0.08$ & $1.66 \pm 0.10$ \\
\hline Benzioni & 2017 & Low & $5.81 \pm 0.46$ & $7.54 \pm 1.02$ & $5.52 \pm 0.72$ & $8.86 \pm 1.56$ & $1.32 \pm 0.03$ & $1.48 \pm 0.07$ \\
\hline Benzioni & 2018 & High & $5.26 \pm 0.16$ & $5.63 \pm 0.46$ & $6.17 \pm 0.38$ & $6.62 \pm 0.71$ & $1.50 \pm 0.05$ & $1.47 \pm 0.03$ \\
\hline
\end{tabular}

* represents a significant difference $(P<0.05, t$-test) between years for the same treatment of the same cultivar. No significant difference was found between treatments. Different letters represent a significant effect of the year $(P<0.05$, two-way ANOVA). The treatment or the interaction between year and treatment did not have a significant effect.

Fruit development in the 2018 season started ca. one month earlier than in 2017 in both cultivars (Figure 2). Although Hazerim and Benzioni were under opposite fruit loads (on/off-year), within the same season, seed development parameters showed similarities in the dates of trend shifts and wax accumulation rates. There was a change in seed size and color as its development progressed. In June, when wax accumulation reached $\sim 50 \%$, the seed color changed from green to light brown (Figure 3), and later in August, at full maturation, it shifted to dark brown.

Fruit mass (including seed, seed coat, and pedicel) (Figure 2a) for both cultivars increased gradually from late March until late June in 2017 and late May in 2018, followed by a moderate decrease due to drying of the seed coat. The ratio of fruit mass (Figure 2a) to seed mass (Figure $2 b$ ) in May showed that the seed constitutes $~ 35 \%$ of the fruit mass, whereas in July 2017 and August 2018, it amounted to $65 \%$ of the fruit mass. In July 2017 and August 2018, it was not possible to take unbiased fruit samples because $\sim 20 \%$ of the seeds had matured, dried, and fallen to the ground.

In parallel to the drying of the fruit capsule, the seed mass continued to build as the dry seed mass increased, peaking at the end of July in 2017 and the end of June in 2018. Seed development, from fruit set to maximum mass, was 77 days for both cultivars in 2017, and 89 and 98 days in 2018 for Hazerim and Benzioni, respectively (Figure 2c). Water content (Figure 2d) decreased linearly during seed development from $70 \%$ to $3 \%$ in mature seeds, reaching its minimum level on August 23 and July 23, in 2017 and 2018, respectively.

Wax content (Figure 2e) reached the reported limit of $\sim 50 \%$ dry weight [19] at the beginning of June, but wax mass (Figure 2f) continued to increase in July due to the increase in seed mass (Figure 2c). 
a

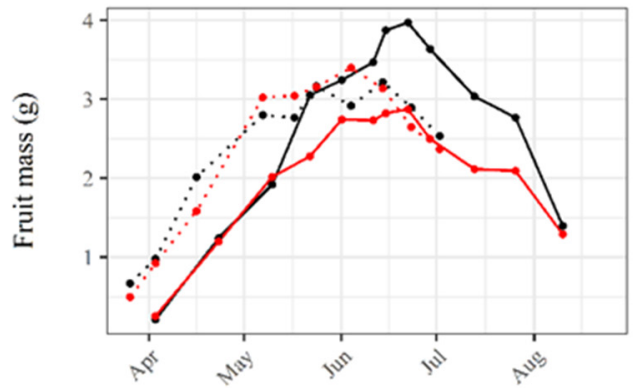

c

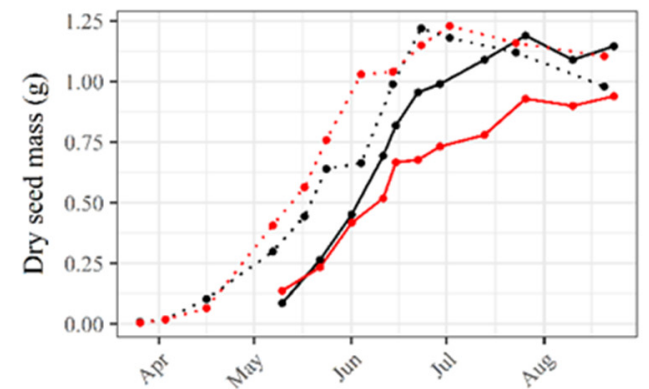

e

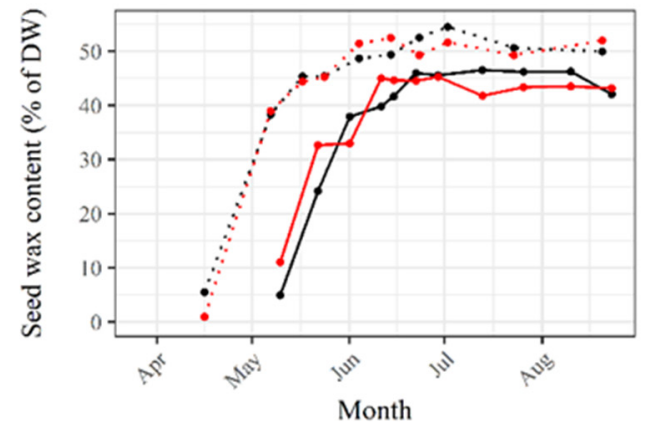

Cultivar $\rightarrow$ Benzioni $\rightarrow$ Hazerim

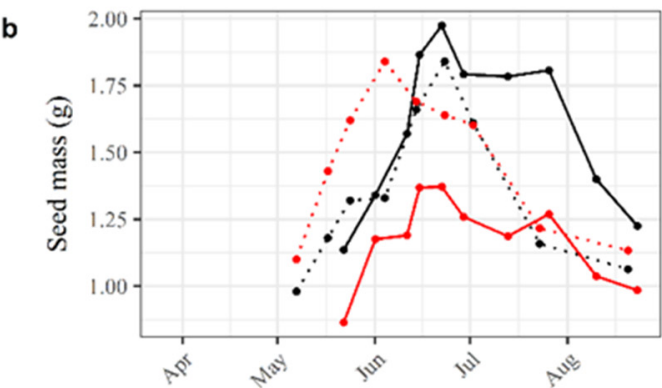

d
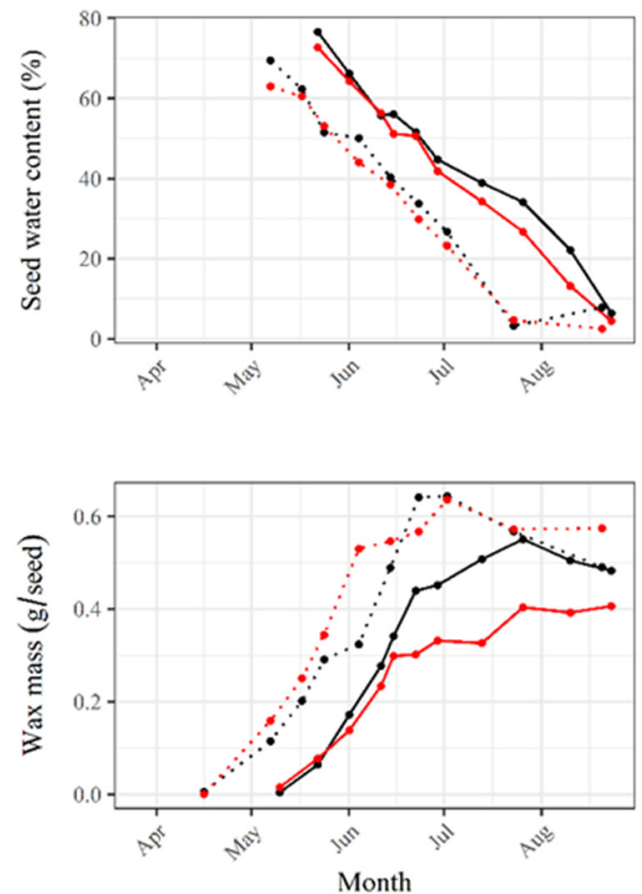

Year $-2017 \quad \cdots \quad 2018$

Figure 2. Seed development parameters for cvs. Benzioni (black) and Hazerim (red) in 2017 (solid lines) and 2018 (dashed lines). Fruit mass (a), seed mass (b), dry seed mass (c), and seed water content (d) values are the means of 12 seeds. Seed wax content (e) and wax mass produced (f) were calculated from a sample of 30 seeds. Seed maturation seemed to take place one month earlier in 2018 than in 2017. DW, dry weight.

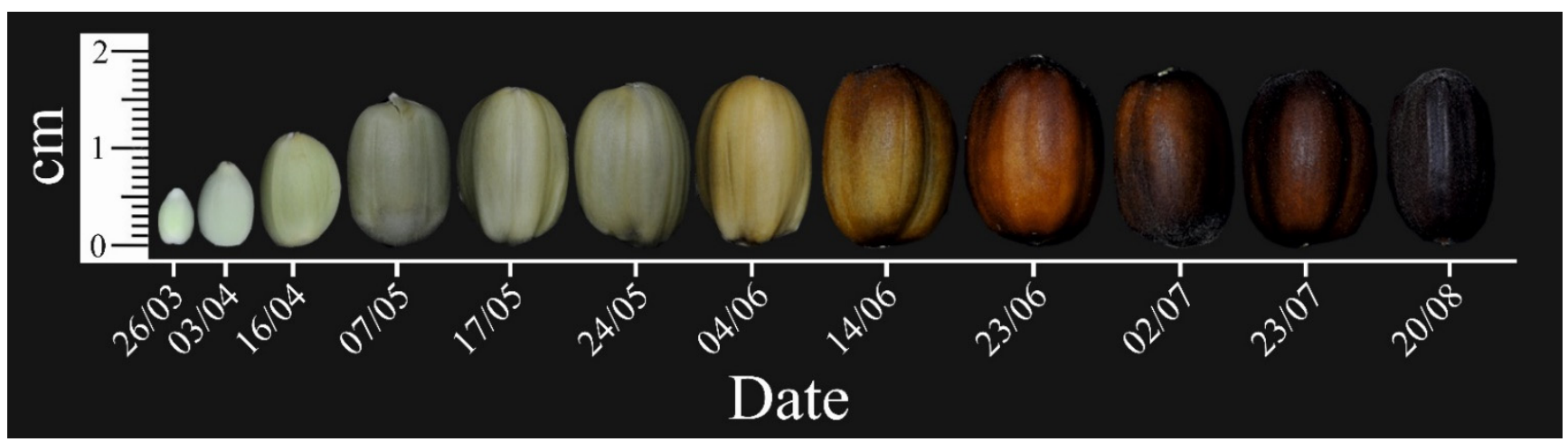

Figure 3. Benzioni seed development scale in 2018. 


\section{Discussion}

The two cultivars that were tested in the current study, Hazerim and Benzioni, have similar productivity levels, and both show significant biennial-bearing behavior [21]. Yield load greatly influenced vegetative development: under the high-yield load, growth ceased at the beginning of the summer, and only renewed in the following winter. On the other hand, under the low-yield load, it either extended through the fruit maturation period, as in Hazerim, or resumed immediately after it, as in Benzioni (Figure 1). Fruit are more powerful sinks than vegetative meristems [22,23]; hence, excessive growth in the off-year suggests that it is part of the regulatory mechanism of alternate bearing, through control of the number of "flowering sites" and, consequently, potential fruit, as the current year's growth expresses the following year's yield potential. As in most female jojoba genotypes, flower buds differentiate at every second node [1]; thus, we should expect the number of flowers to be half the number of new nodes per branch. Removal of part of the new shoots (pruning) before an on-year has recently been tested as an efficient tool to control biennial bearing in jojoba without long-term yield reduction, as the yield that is lost in the on-year will be compensated for in the following off-year [21]. Taking these findings together supports our hypothesis that competition between sinks is the main factor controlling alternate bearing.

Removing fruit from the shoot in an on-year did not affect vegetative development, unlike fruit removal in an off-year where the fruitless branches developed ca. two additional nodes than the fruit-bearing ones. This suggests that fruit removal has a local effect on the source-to-sink ratio in branches during the off-year, enabling intensive vegetative growth of fruitless branches. Further evidence for this local effect is the production of extended nodes after removing the fruit during an off-year, as was found for Benzioni in 2017. This outcome is likely because the fruits on the neighboring branches act as a robust sink, and the competition for reserves between fruit and vegetative meristems inhibits growth, as has been reported for avocados and olives [28,29]. Although in Hazerim, fruit removal did not affect node length in the off-year, it produced longer branches with more nodes than the control branches. The different growth patterns under fruit load could be associated with different cultivar characteristics or genetic backgrounds, even though both cultivars were selected by the same criteria-intense vegetative development and high yield [5].

Fruit development took from five to six months, from anthesis to mature seed, similar to wild jojoba populations [1]. Descriptions of the mode of wax accumulation in jojoba seeds in commercial plantations, as described in detail here (Figure 2), are scarce in the literature. Initially, the young seed contains mainly water, the content of which decreases linearly with time, being replaced with wax (Figure $2 \mathrm{~d}$,e). The wax synthesis pathway in jojoba has recently been described by Alotaibi et al. [30] and Sturtevant et al. [31]. The fruit and seed reach their peak weight in parallel to wax accumulation reaching ca. $50 \%$ of dry weight. Interestingly, unrelated to fruit load, when oil accumulation starts earlier in the season, the final wax content is higher (Figure 2e). The wax mass continues to increase until the seed water content reaches ca. $2 \%$; thereafter, the seeds continue to dry, but the seed mass and wax content remain relatively constant. The process of wax accumulation is rapid—it took ca. six weeks in 2017 and ca. nine weeks in 2018 (Figure 2f)—and requires a large amount of energy. Wallace and Rundel [32] estimated that $30-40 \%$ of the plant's energetic resources are allocated to reproduction. This high energetic demand in on-years can be met through intense photosynthetic activity, as reported in olive [33,34], or through depletion of energy reserves, as found in citrus [22]. There is an indication of jojoba's use of reserves, as a previous study found a reduction in nonstructural carbohydrates and starch between April and July [35], corresponding to the wax accumulation period (Figure 2f). Moreover, vegetative development in both cultivars stopped in this period (Figure 1).

Based on our results, we can divide the female reproductive cycle in jojoba into three phases: (i) vegetative growth, anthesis, and fruit set, from December till mid-April; (ii) wax accumulation between April and June, along with growth cessation; and (iii) fruit 
ripening and renewal of vegetative development between June and August. In an off-year, vegetative growth starts immediately, whereas in an on-year, growth will resume only at the end of January of the following year (the beginning of the off-year).

A visual indication of the ripening process is the change in seed color during fruit development and maturation (Figure 3). Peel color shifts from light green to light brown, the latter representing maximum weight accumulation of the seed and the beginning of the drying process; the subsequent dark brown color represents full seed maturation.

With respect to the seeds' developmental parameters, alternate yield load mainly affected the dry seed and wax masses, which were smaller under high load (Table 2). Purcell et al. [18] described this effect in jojoba, and it occurs in other species as well, such as olive [36], mango [37], and apple [38]. It is associated with the source-to-sink ratio, as the number of seeds is higher in the on-year (Table 2). Nevertheless, the higher wax mass per seed in the off-year did not compensate for the lower number of seeds, and the total wax yield, which is of interest in this crop, was higher in the on-year.

Table 2. Effect of yield on dry seed mass, wax mass, number of seeds per plant, and wax yield per plant in Hazerim and Benzioni. Seed and wax mass values are the means of 12 seeds per cultivar. We calculated the number of seeds per plant by dividing the total yield by the seed mass, and then dividing by the number of female plants per hectare (Equation (1)). Wax yield per plant was calculated by multiplying wax mass by the number of seeds.

\begin{tabular}{ccccccccc}
\hline \multirow{2}{*}{ Cultivar } & \multicolumn{2}{c}{ Dry Seed Mass (g) } & \multicolumn{2}{c}{$\begin{array}{c}\text { Wax Mass } \\
\text { (g seed }\end{array}$} & \multicolumn{2}{c}{$\begin{array}{c}\text { No. of Seeds } \\
\text { Plant }^{-1}\end{array}$} & \multicolumn{2}{c}{$\begin{array}{c}\text { Wax Yield } \\
\text { (kg plant }^{-1} \text { ) }\end{array}$} \\
\cline { 2 - 10 } & \multicolumn{2}{c}{ Yield Load } & \multicolumn{2}{c}{ Yield Load } & \multicolumn{2}{c}{ Yield Load } & \multicolumn{2}{c}{ Yield Load } \\
\cline { 2 - 10 } & High & Low & High & Low & High & Low & High & Low \\
\hline Hazerim & 0.94 & 1.11 & 0.40 & 0.57 & 6907 & 2350 & 2.76 & 1.35 \\
Benzioni & 0.98 & 1.15 & 0.46 & 0.48 & 3780 & 2402 & 1.74 & 1.15 \\
\hline
\end{tabular}

Under different yield loads, in both cultivars, seed characteristics, such as water and wax content, were similar within the same season (Figure 2d,e). Moreover, in both cultivars, seed development occurred about a month earlier in 2018 than in 2017. This might have been due to the environmental conditions, with a warmer winter in 2018 (Figure S1), accelerating the flowering and fruit set process. The earlier development in 2018 was also reflected by early vegetative growth (Figure 1 ). In jojoba, high temperatures $\left(33 / 28{ }^{\circ} \mathrm{C}\right.$ day/night) during fruit development were found to enhance the rate of dry matter accumulation in the seed, although the final size of the mature seed was higher under an $18 / 13{ }^{\circ} \mathrm{C}$ day/night temperature regime [39]. This was attributed to the long development period.

\section{Conclusions}

A two-year study showed that jojoba's vegetative growth is affected by yield load: under low yields, the plant produces $\sim 35 \%$ more new nodes, which are on average, $12 \%$ longer. The growing period is dependent on yield load as, after an on-year, there is a delay in growth renewal. As for seed development, there is a decrease in the number of seeds and an increase in seed wax mass under low yield, but the total wax yield per hectare is lower than in the on-year. The wax accumulation rate, based on a percentage of dry weight, was affected by year and not by fruit load. However, on-year seeds ceased growing earlier, resulting in smaller seeds and an overall lower amount of wax per seed.

Although the yield of Hazerim was 2.5 times higher in the on-year than in the off-year, whereas that of Benzioni was only 1.3 times higher, the same effects of the higher load on node development, branch length, and seed mass were apparent. This raises the question of whether there is a yield load threshold beyond which growth and seed development performance decline. 
Supplementary Materials: The following are available online at https:/ / www.mdpi.com/article / 10.3390/agronomy11050889/s1: Figure S1: Minimum (dashed lines) and maximum (solid lines) temperatures measured in 2016/17 (black) and 2017/18 (red). Data gathered from ims.gov.il, Beer Sheva station.

Author Contributions: Conceptualization, A.P., N.T.-Z., and A.D.; methodology, A.P. and A.D; formal analysis, A.P.; writing—original draft preparation, A.P. and A.D; writing-review and editing, N.T.-Z.; investigation, A.P; visualization, A.P.; project administration, A.D. and N.T.-Z.; funding acquisition, A.D. and N.T.-Z. All authors have read and agreed to the published version of the manuscript.

Funding: This research was funded by the Chief Scientist of the Israel Ministry of Agriculture \& Rural Development, grant number 20-13-0025.

Acknowledgments: We thank Yulia Sobbotin for technical assistance and Ronen Rotschild (Jojoba Israel, Kibbutz Hatzerim, Israel) for his advice and for sharing the yield data.

Conflicts of Interest: The authors declare no conflict of interest.

\section{References}

1. Gentry, H.S. The natural history of jojoba (Simmondsia chinensis) and its cultural aspects. Econ. Bot. 1958, 12, 261-295. [CrossRef]

2. Reddy, M.P.; Chikara, J. Biotechnology advances in jojoba (Simmondsia chinensis). In Desert Plants; Springer: Berlin/Heidelberg, Germany, 2010; pp. 407-421.

3. Benzioni, A. Jojoba research as basis for domestication of jojoba in Israel. Isr. J. Plant Sci. 2006, 54, 157-167. [CrossRef]

4. Sánchez, M.; Avhad, M.R.; Marchetti, J.M.; Martínez, M.; Aracil, J. Jojoba oil: A state of the art review and future prospects. Energy Convers. Manag. 2016, 129, 293-304. [CrossRef]

5. Benzioni, A. Jojoba domestication and commercialization in Israel. Hortic. Rev. Westport N. Y. 1995, 17, $233-266$.

6. Eilat, Y.; (Jojoba Israel, Kibbutz Hatzerim, Israel). Personal communication, 2021.

7. Wisniak, J. Potential uses of jojoba oil and meal-A review. Ind. Crops Prod. 1994, 3, 43-68. [CrossRef]

8. Tietel, Z.; Kahremany, S.; Cohen, G.; Ogen-Shtern, N. Medicinal properties of jojoba (Simmondsia chinensis). Isr. J. Plant Sci. 2021, 1, 1-10. [CrossRef]

9. Gisser, H.; Messina, J.; Chasan, D. Jojoba oil as a sperm oil substitute. Wear 1975, 34, 53-63. [CrossRef]

10. Busson-Breysse, J.; Farines, M.; Soulier, J. Jojoba wax: Its esters and some of its minor components. J. Am. Oil Chem. Soc. 1994, 71, 999-1002. [CrossRef]

11. Tobares, L.; Frati, M.; Guzmán, C.; Maestri, D. Agronomical and chemical traits as descriptors for discrimination and selection of jojoba (Simmondsia chinensis) clones. Ind. Crops Prod. 2004, 19, 107-111. [CrossRef]

12. Buchmann, S.L. Floral biology of jojoba (Simmondsia chinensis), an anemophilous plant. Desert Plants 1987.

13. Prat, L.; Botti, C.; Fichet, T. Effect of plant growth regulators on floral differentiation and seed production in Jojoba (Simmondsia chinensis (Link) Schneider). Ind. Crops Prod. 2008, 27, 44-49. [CrossRef]

14. Dunstone, R.L. The reproductive cycle of jojoba. In Seventh International Conference on Jojoba and Its Uses: Proceedings; American Oil Chemists' Society: Champaign, IL, USA, 1989; pp. 50-59.

15. Tel Zur, N.; Rothschild, R.; Zurgil, U.; Vaknin, Y. Characterization of Flowering Time and Pollen Production in Jojoba (Simmondsia chinensis) towards a Strategy for the Selection of Elite Male Genotypes. Agronomy 2020, 10, 592. [CrossRef]

16. Dunstone, R.L. Jojoba flower buds: Temperature and photoperiod effects in breaking dormancy. Aust. J. Agric. Res. 1980, 31, 727-737. [CrossRef]

17. Ferriere, J.; Milthorpe, P.L.; Dunstone, R.L. Variability in chilling requirements for the breaking of flower bud dormancy in jojoba (Simmondsia chinensis [Link] Schneider). J. Hortic. Sci. 1989, 64, 379-387. [CrossRef]

18. Purcell, H.C.; Abbott, T.P.; Holser, R.A.; Phillips, B.S. Simmondsin and wax ester levels in 100 high-yielding jojoba clones. Ind. Crops Prod. 2000, 12, 151-157. [CrossRef]

19. Nelson, J.M.; Watson, J.E. Nitrogen fertilization effects on jojoba seed production. Ind. Crops Prod. 2001, 13, 145-154. [CrossRef]

20. Bakeer, S.M.; Makpoul, K.R.; Abou-Ellail, M. Evaluation of ten jojoba clones (Simmondsia chinensis) grown under Middle Sinai conditions. Ind. Crops Prod. 2017, 107, 30-37. [CrossRef]

21. Lazare, S.; Zipori, I.; Cohen, Y.; Haberman, A.; Goldshtein, E.; Ron, Y.; Rotschild, R.; Dag, A. Jojoba pruning: New practices to rejuvenate the plant, improve yield and reduce alternate bearing. Sci. Hortic. 2021, 277, 109793. [CrossRef]

22. Monselise, S.P.; Goldschmidt, E.E. Alternate bearing in fruit trees. Hortic. Rev. 1982, 4, 128-173.

23. Smith, H.M.; Samach, A. Constraints to obtaining consistent annual yields in perennial tree crops. I: Heavy fruit load dominates over vegetative growth. Plant. Sci. 2013, 207, 158-167. [CrossRef] [PubMed]

24. Haim, D.; Shalom, L.; Simhon, Y.; Shlizerman, L.; Kamara, I.; Morozov, M.; Sadka, A. Alternate bearing in fruit trees: Fruit presence induces polar auxin transport in citrus and olive stem and represses IAA release from the bud. J. Exp. Bot. 2021, 72, 2450-2462. [CrossRef]

25. Yermanos, D.M.; Duncan, C.C. Quantitative and qualitative characteristics of jojoba seed. J. Am. Oil Chem. Soc. 1976, 53, 80-82. [CrossRef] 
26. Abdel mohsen, M.; Abd alltif, A. Selection of some promising jojoba (Simmondsia chinensis) genotypes: Evaluation of tree growth and productivity. Egypt. J. Plant Breed. 2015, 19, 1953-1962. [CrossRef]

27. Rotschild, R.; (Jojoba Israel, Kibbutz Hatzerim, Israel). Personal communication, 2021.

28. Scholefield, P.B.; Sedgley, M.; Alexander, D.M. Carbohydrate cycling in relation to shoot growth, floral initiation and development and yield in the avocado. Sci. Hortic. 1985, 25, 99-110. [CrossRef]

29. Dag, A.; Bustan, A.; Avni, A.; Tzipori, I.; Lavee, S.; Riov, J. Timing of fruit removal affects concurrent vegetative growth and subsequent return bloom and yield in olive (Olea europaea L.). Sci. Hortic. 2010, 123, 469-472. [CrossRef]

30. Alotaibi, S.S.; Elseehy, M.M.; Aljuaid, B.S.; El-Shehawi, A.M. Transcriptome analysis of jojoba (Simmondsia chinensis) during seed development and liquid wax ester biosynthesis. Plants 2020, 9, 588. [CrossRef] [PubMed]

31. Sturtevant, D.; Lu, S.; Zhou, Z.-W.; Shen, Y.; Wang, S.; Song, J.-M.; Zhong, J.; Burks, D.J.; Yang, Z.-Q.; Yang, Q.-Y.; et al. The Genome of jojoba (Simmondsia chinensis): A taxonomically isolated species that directs wax ester accumulation in its seeds. Sci. Adv. 2020, 6, eaay3240. [CrossRef] [PubMed]

32. Wallace, C.S.; Rundel, P.W. Sexual dimorphism and resource allocation in male and female shrubs of Simmondsia chinensis. Oecologia 1979, 44, 34-39. [CrossRef] [PubMed]

33. Bustan, A.; Avni, A.; Lavee, S.; Zipori, I.; Yeselson, Y.; Schaffer, A.A.; Riov, J.; Dag, A. Role of carbohydrate reserves in yield production of intensively cultivated oil olive (Olea europaea L.) trees. Tree Physiol. 2011, 31, 519-530. [CrossRef] [PubMed]

34. Bustan, A.; Dag, A.; Yermiyahu, U.; Erel, R.; Presnov, E.; Agam, N.; Ben-Gal, A. Fruit load governs transpiration of olive trees. Tree Physiol 2016, 36, 380-391. [CrossRef]

35. Khalafalla, M.S.; Palzkill, D.A. Seasonal patterns of carbohydrates and proline in jojoba clones that differ in frost susceptibility. HortScience 1990, 25, 103-105. [CrossRef]

36. Trentacoste, E.R.; Puertas, C.M.; Sadras, V.O. Effect of fruit load on oil yield components and dynamics of fruit growth and oil accumulation in olive (Olea europaea L.). Eur. J. Agron. 2010, 32, 249-254. [CrossRef]

37. Koirala, A.; Walsh, K.B.; Wang, Z.; McCarthy, C. Deep learning for real-time fruit detection and orchard fruit load estimation: Benchmarking of 'MangoYOLO'. Precis. Agric. 2019, 20, 1107-1135. [CrossRef]

38. Naor, A.; Naschitz, S.; Peres, M.; Gal, Y. Responses of apple fruit size to tree water status and crop load. Tree Physiol. 2008, 28, 1255-1261. [CrossRef] [PubMed]

39. Wardlaw, I.F.; Dunstone, R.L. Effect of temperature on seed development in jojoba (Simmondsia chinensis (Link) Schneider). I. Dry matter changes. Aust. J. Agric. Res. 1984, 35, 685-691. [CrossRef] 